\title{
Design Thinking e Abordagem das Capacitações Uma Proposta De Integração
}

http://dx.doi.org/10.21527/2237-6453.2019.47.46-61

Recebido em: 19/11/2017

Aceito em: 2/10/2018

Roberta Cristina Redante, ${ }^{1}$ Luiz Fernando Fritz Filho, ${ }^{2}$ Janine Fleith de Medeiros ${ }^{3}$

\begin{abstract}
RESUMO
Em um planeta que enfrenta cada vez mais desafios, a busca pela qualidade de vida é uma constante em distintas culturas, etnias e classes sociais. As pessoas desejam ter a oportunidade de viver a vida que, para elas, é significativa, a partir da liberdade de escolha diante das opções que lhes apresentem maior valor, princípios centrais da abordagem das capacitações. Ao mesmo tempo, para que isso seja possível, muitos problemas complexos precisam ser sanados, apresentando-se como uma alternativa o design thinking. Conceitualmente, o design thinking pode ser compreendido como uma abordagem iterativa e centrada no ser humano para a resolução de problemas. Assim, este artigo tem por objetivo refletir sobre a possibilidade de integração da abordagem das capacitações com a abordagem do design thinking visando a configurar, a partir da referida integração, uma estratégia para o desenvolvimento e consequente aumento do bem-estar social na resolução dos problemas complexos atuais. As conclusões demonstram que esta integração pode ser uma forma de contribuir para a ampliação das liberdades individuais das pessoas, e na solução dos desafios e problemas complexos enfrentados pelas nações, por meio da utilização dos processos e valores do design thinking.
\end{abstract}

Palavras-chave: Design thinking. Abordagem das capacitações. Desenvolvimento. Problemas complexos.

\section{DESIGN THINKING AND CAPABILITY APPROACH: AN INTEGRATION PROPOSAL}

\section{ABSTRACT}

On a planet facing ever more challenges, the search for quality of life is a constant in cultures, ethnicities, social classes. The people want to have the opportunity to live the life that for them is meaningful, based on the freedom to choose from the most valuable options, central principles of the capability approach. At the same time, for this to be possible, many wicked problems need to be remedied, and design thinking presents itself as an alternative. Conceptually, design thinking can be understood as an iterative, human-centered approach to problem solving. Thus, this article aims to reflect on the possibility of integrating the capability approach with the design thinking approach in order to configure, from the said integration, a strategy for the development and consequent increase of the social welfare in the resolution of the wicked problems. The conclusions show that such integration can be a way of contributing to the extension of individual substantive freedoms, and in solving the complex challenges and problems faced by nations, through the use of design thinking processes and values.

Keywords: Design thinking. Capability approach. Development. Complex problems.

\footnotetext{
${ }^{1}$ Mestre em Administração pela Universidade de Passo Fundo (UPF). betaredante@gmail.com

${ }^{2}$ Doutor em Desenvolvimento Rural pela Universidade Federal do Rio Grande do Sul (UFRGS). Professor da Universidade de Passo Fundo (UPF).fritz@upf.br

${ }^{3}$ Doutora em Engenharia de Produção pela Universidade Federal do Rio Grande do Sul (UFRGS). Professora da Universidade de Passo Fundo (UPF). janine@upf.br
} 
Vive-se em uma sociedade que enfrenta problemas cada vez mais complexos, com a necessidade de transformação mostrando-se algo significativo. Em todo o planeta encontram-se problemas semelhantes: (i) o acesso à saúde não está disponível a todos; (ii) a educação tem muitos pontos falhos; (iii) os recursos financeiros concentram-se nas mãos de poucos; (iv) o consumo de energia ultrapassa a capacidade de produção do planeta, entre outros (BROWN, 2008). Ao mesmo tempo, em todo o planeta as pessoas demandam uma maior qualidade de vida. Entretanto, enquanto os indivíduos desejam e focam na busca de uma vida com maior qualidade, os líderes das nações muitas vezes se concentram apenas no crescimento econômico nacional (NUSSBAUM, 2011).

$O$ progresso de um país por muitos anos foi medido considerando o crescimento econômico decorrente do Produto Interno Bruto (PIB) per capita (NUSSBAUM, 2011), porém o desenvolvimento vai muito além do que apenas concepções relacionadas à renda e acumulação de riquezas (SEN, 2000). Sabe-se que o aumento do PIB não é um expoente para o aumento da qualidade da vida das pessoas, e os números que relatam a prosperidade nacional podem não fazer diferença para aqueles que vivem uma vida de desigualdade e privação (NUSSBAUM, 2011). As liberdades desfrutadas pelos membros da sociedade dependem também de outros determinantes, como as disposições sociais e econômicas (SEN, 2000).

Diante do exposto, a abordagem das capacitações estabeleceu-se como um caminho alternativo à abordagem do PIB (NUSSBAUM, 2011). Pioneiramente, foi desenvolvida pelo economista e filósofo Amartya Sen (2000, 2001), e posteriormente pela filósofa Martha Nussbaum (2000, 2011), entre outros autores. Teoricamente, seu enfoque nas liberdades humanas contrasta com visões mais restritas de desenvolvimento, como as que identificam desenvolvimento com crescimento do PIB, aumento da renda pessoal, industrialização, avanço tecnológico ou modernização social (SEN, 2000). Além disso, a abordagem de Sen influenciou e continua a influenciar o Índice de Desenvolvimento Humano (IDH) do Programa das Nações Unidas para o Desenvolvimento (Pnud). Idealizado por UI Haq, mas criado com auxílio dos trabalhos de Sen, é um índice que visa a medir o desenvolvimento dos países considerando, além das questões econômicas, os aspectos sociais (PNUD, 2018). ${ }^{4}$

Paralelamente, tem-se o design thinking. Conceitualmente, o design thinking sistematiza orientações para que soluções aos problemas complexos sejam possíveis. Focado na inovação, caracteriza-se por ser uma abordagem criativa, iterativa, centrada no ser humano e que busca encontrar as melhores ideias para a resolução definitiva dos problemas (BROWN, 2008). Além disso, objetiva a acessibilidade e a relevância para a resolução de problemas inovadores e potencialmente estratégicos em várias disciplinas (SHAPIRA; KETCHIE; MERET, 2017).

A partir dessa compreensão, entende-se que para o aumento da qualidade de vida de uma nação é necessário que as pessoas tenham direito de escolha, para que possam viver e valorizar a vida que escolheram, e tenham a oportunidade de ser agentes desse

\footnotetext{
${ }^{4} \mathrm{O}$ Índice de Desenvolvimento Humano (IDH) visa a atuar como uma medida geral do desenvolvimento humano. $\mathrm{O}$ IDH mede o progresso de uma nação avaliando questões que abrangem renda, saúde e educação, mas sem contemplar diversos outros aspectos relevantes do desenvolvimento humano. Desde 1990, o índice é publicado anualmente e pode ser considerado uma referência mundial (PNUD, 2018).
} 
processo. Para isso, porém, é necessário que haja o suporte de diversas instituições que tornem isto possível. Propõe-se assim que a união das abordagens pode ser um meio para operacionalizar as capacidades humanas, possibilitando que as instituições que podem impactar no desenvolvimento humano possuam uma alternativa na busca por soluções que possibilitem liberdades substantivas às pessoas.

Este artigo, portanto, tem por objetivo refletir sobre a possibilidade de integração da abordagem das capacitações de Nussbaum $(2000,2011)$ e Sen $(2000,2011)$ com a abordagem do design thinking, na busca de contribuir com o desenvolvimento e consequente aumento do bem-estar social na resolução dos problemas complexos atuais. Visa a (i) identificar e compreender as aproximações possíveis entre as duas abordagens, assim como (ii) analisar suas semelhanças e diferenças. Com isso, busca-se delinear uma nova estratégia para o desenvolvimento e consequente aumento do bem-estar social na resolução dos problemas complexos atuais.

Inicialmente ambas as abordagens serão caracterizadas e, posteriormente, serão apontados os possíveis elos entre elas. Por fim, uma sistematização será estabelecida, visando a orientar os pesquisadores de diferentes áreas sobre como as duas abordagens podem ser utilizadas conjuntamente.

\section{ABORDAGEM DAS CAPACITAÇÕES}

A abordagem das capacitações (capability approach) centra-se na vida humana, ou seja, no que as pessoas são efetivamente capazes de fazer e de ser, e não apenas em alguns objetos separados de conveniência (como rendas ou mercadorias). Propõe uma base informacional mais ampla, em que se possa ter maiores condições de avaliar o bem-estar humano a partir da capacidade que as pessoas têm de escolher a vida que elas, com justiça, valorizam. É para enfrentar este desafio teórico que a abordagem das capacitações foi proposta. Essa abordagem está apoiada na noção de liberdade, na qual o que realmente importa é a possibilidade que o indivíduo tem de ser e fazer aquilo que ele julga melhor para si próprio, a liberdade que ele tem para valorizar aquilo que ele julga melhor, dentro dos princípios da justiça (SEN, 2000).

Considerando esse enfoque, destaca-se que as concepções de liberdade estão relacionadas à possibilidade de as pessoas exercerem seu papel de agente, ou seja, de poderem realizar livremente atividades ou alcançar determinados estados valorizados individual ou socialmente (SEN, 2000). Dessa forma, as pessoas tornam-se tanto beneficiárias do desenvolvimento como agentes do processo, com participação ativa e livre (ANDRADE et al., 2016). As pessoas possuem a oportunidade de modificar o mundo ao seu redor e a si mesmas, podendo atuar como participantes ativos nas decisões coletivas que envolvam o seu destino e mobilizem sua visão de mundo (KERSTENETZKY, 2011).

Sen sugere uma abordagem que analise as situações sociais de uma forma multidimensional. Por exemplo, se uma pessoa tem uma renda alta, mas também é muito propensa a uma doença crônica, ou é afetada por alguma deficiência física grave, então ela não precisa necessariamente ser vista como estando em grande vantagem pela simples razão de ter uma renda alta. É provável que ela tenha mais de um dos meios para viver bem (ou seja, uma renda elevada), mas enfrenta dificuldades em converter essa vantagem em boa vida devido às adversidades da doença e à deficiência física. Deve-se anali- 
sar o quanto ela pode de fato realizar, se assim o deseja, com um estado de boa saúde, bem-estar e aptidão, para fazer o que tem razão para valorizar. Compreender que não basta possuir os recursos necessários para uma vida humana satisfatória sem possuir qualidade de vida e demais aspectos humanos ajudam a gerar um aumento significativo do alcance do exercício avaliativo (SEN, 2011).

A abordagem das capacitações aponta para um foco informacional de modo a avaliar vantagens individuais globais, julgadas com relação à oportunidade, cujos diferentes usos podem surgir em razão da natureza das questões envolvidas e dos dados e material informativo utilizados. Também aponta para a relevância central da desigualdade de capacitações na avaliação das disparidades sociais (SEN, 2011). A escolha de um foco informacional centrado nessa abordagem pode auxiliar a análise e as escolhas de políticas públicas, pois podem ser influenciadas por informações nas quais a própria abordagem da capacitação se concentra (isto é, podem utilizar informações referentes às possibilidades de realização dessas oportunidades), embora não proponha uma fórmula específica.

Conforme esclarece Fritz, Sen sugere:

[...] uma abordagem que analise as situações sociais de uma forma multidimensional. Ou seja, para a compreensão de alguma parte da realidade social é preciso focar a análise na incorporação de variáveis quantitativas e indo além delas. É importante, sim, analisar aquilo que as pessoas têm acesso - como bens e mercadorias - entretanto, é preciso perceber em que tipo de mercado e de que forma essas pessoas são expostas a essas oportunidades de aquisição (FRITZ, 2009, p. 42).

Percebe-se que o núcleo da abordagem das capacitações não é apenas o que uma pessoa faz (oportunidade no sentido estrito), mas também aquilo que ela, de fato, é capaz de fazer (oportunidade no sentido amplo). A capacitação consiste nas combinações alternativas de funcionamentos cuja realização é factível para uma determinada pessoa; consiste na liberdade substantiva de realizar combinações alternativas de funcionamentos, ou, menos formalmente expresso, a liberdade para ter estilos de vida diversos (SEN, 2000).

As liberdades substantivas podem ser consideradas os estados finais desejados pelas pessoas, e as liberdades instrumentais são os meios para se atingir tais estados (ANDRADE et al., 2016). Ou seja, as liberdades são meios e fins para a promoção do desenvolvimento, atuando como instrumentos para a expansão das liberdades das pessoas. As liberdades instrumentais referem-se aos direitos e oportunidades que possam contribuir para a capacidade geral de as pessoas viverem mais livremente, contribuindo assim para a promoção do desenvolvimento (SEN, 2000).

As liberdades instrumentais possuem o efeito complementar e sinérgico entre si e podem contribuir para a expansão da liberdade humana em geral (SEN, 2000). Quando utilizadas juntas, suplementam-se mutuamente e influenciam positivamente a expansão umas das outras, possuindo maior efeito na promoção do desenvolvimento. As liberdades instrumentais identificadas por Sen (2000) classificam-se em cinco tipos: liberdades políticas, facilidades econômicas, oportunidades sociais, garantia de transparência e segurança protetora, representando diretamente os tipos de crescimento das capacidades humanas em geral. 
As liberdades políticas estão ligadas a questões de liberdade de expressão, de escolha de partidos políticos e direito ao voto. As facilidades econômicas relacionam-se com os recursos disponíveis, às condições de mercado e acesso a financiamentos. Já as oportunidades sociais são as disposições relacionadas à educação, saúde, entre outros fatores. As garantias de transparência, por sua vez, abrangem os direitos à revelação e transparência das contas públicas. Por fim, a segurança protetora busca proporcionar uma rede de segurança social, visando a evitar a miséria da população. A partir das liberdades instrumentais, é possível compreender melhor os objetivos do desenvolvimento humano, pois por meio de suas trocas os indivíduos tornam-se livres para optar por uma vida que eles com razão apreciam (SEN, 2000).

A liberdade substantiva leva em consideração uma abordagem mais ampla da oportunidade. Ele avalia o processo de escolha, as oportunidades reais, a aptidão real das pessoas ao exercer a liberdade de escolha. Nesse contexto:

[...] Com relação às oportunidades, a vantagem de uma pessoa é considerada menor que a de outra se ela tem menos capacidade - menos oportunidade real - para realizar as coisas que tem razão para valorizar. O foco aqui é a liberdade que uma pessoa realmente tem para fazer isso ou ser aquilo - coisas que ela pode valorizar fazer ou ser. Obviamente, é muito importante para nós sermos capazes de realizar as coisas que mais valorizamos. Mas a ideia de liberdade também diz respeito a sermos livres para determinar o que queremos, o que valorizamos e, em última instância, o que decidimos escolher. O conceito de capacidade está, portanto, ligado intimamente com o aspecto de oportunidade da liberdade, visto com relação a oportunidades "abrangentes", e não apenas se concentrando no que acontece na "culminação" (SEN, 2011, p. 266).

Quanto mais liberdade uma pessoa tiver, mais oportunidades para buscar seus objetivos ela terá. Liberdade que é relacionada com as reais aptidões que cada um tem para realizar o que valoriza, bem como com o processo por meio do qual isso acontece. Mais do que liberdade instrumental, é preciso direcionar-se para a liberdade substantiva. Nesse sentido:

O êxito de uma sociedade deve ser avaliado [...] primordialmente segundo as liberdades substantivas que os membros dessa sociedade desfrutam.

[...] Ter mais liberdade para fazer as coisas que são justamente valorizadas é (1) importante por si mesmo para a liberdade global da pessoa e (2) importante porque favorece a oportunidade de a pessoa ter resultados valiosos.

[...] a liberdade não é apenas a base da avaliação de êxito e fracasso, mas também um determinante principal da iniciativa individual e da eficácia social. Ter mais liberdade melhora o potencial das pessoas para cuidar de si mesmas e para influenciar o mundo, questões centrais para o processo de desenvolvimento (SEN, 2011, p. 33).

Segundo Zambam, o valor moral substantivo da liberdade em Sen é uma condição indispensável para que se possa caracterizar uma sociedade justa, porque dessa compreensão dependem as condições, as instituições, as estruturas e os demais organismos intermediários que compõem a dinâmica da organização e do funcionamento de uma sociedade que defende, fortalece e promove a liberdade. Assim, sua privação compro- 
mete a realização das pessoas, ao passo que seu exercício determina a qualidade e as perspectivas da vida humana, da estrutura interna e das relações externas da sociedade (ZAMBAM, 2012, p. 40).

A possibilidade de escolher integra a condição de existência livre do homem; sem essa característica ocorre a redução da pessoa à condição de objeto, isto é, a limitação ou a própria negação da sua humanidade. [...] Quando a liberdade é limitada, preferencialmente, a um meio para justificar ou impor certos objetivos, por mais nobres que possam parecer, perde seu objetivo central e sacrifica seu valor moral substantivo. Tal postura não possui justificativa (ZAMBAM, 2012, p. 42).

A abordagem toma cada pessoa como um fim, questionando não apenas sobre o bem-estar, mas sobre as oportunidades disponíveis para cada pessoa viver a vida que valoriza (NUSSBAUM, 2011; SEN, 2000). Sendo assim, somente os fins têm importância intrínseca, enquanto os meios são instrumentais para alcançar o objetivo de maior bem-estar, justiça e desenvolvimento (ROBEYNS, 2005). Esta é uma abordagem adequada para a avaliação da qualidade de vida e de questões de justiça social e igualdade (NUSSBAUM, 2011; ROBEYNS, 2005). Ademais, ela se concentra na escolha ou na liberdade, afirmando que as sociedades possuem um conjunto de oportunidades ou liberdades substantivas que as pessoas podem ou não exercitar, cabendo a cada um a escolha (NUSSBAUM, 2011).

A abordagem das capacitações contribui para avaliação do bem-estar individual e dos arranjos sociais, do desenho de políticas e propostas sobre a mudança social na sociedade, e pode ser usada para avaliar vários aspectos do bem-estar das pessoas, como a desigualdade, a pobreza, o bem-estar de um indivíduo ou dos membros de um grupo (ROBEYNS, 2005). Destaca-se, entretanto, que esta não é uma teoria que possa explicar estes fenômenos, mas ao invés disso, fornece uma ferramenta e uma estrutura que possibilitam conceitua-los e analisá-los. Ela avalia as políticas de acordo com seu impacto nas capacidades das pessoas e abrange todas as dimensões do bem-estar humano (ROBEYNS, 2005).

As concepções dos principais autores que abordam o tema, Amartya Sen e Martha Nussbaum, apesar de estarem intimamente relacionadas, também possuem algumas questões divergentes. Nussbaum e Sen têm objetivos diferentes nos seus trabalhos sobre as capacidades. Considerando que no trabalho de Sen a noção de capacitações é principalmente a de uma oportunidade real ou efetiva, a noção de Nussbaum de capacidade volta-se às habilidades das pessoas e traços de personalidade como aspectos de capacitações (ROBEYNS, 2005). O Quadro 1 apresenta uma comparação entre as concepções conceituais propostas pelos dois principais teóricos da abordagem das capacitações, descrevendo as principais divergências entre os dois autores.

No quadro, pode-se analisar que os autores divergem na maneira como as capacitações podem ser abordadas a fim de avaliar a qualidade de vida. Enquanto Sen aborda as capacitações a partir do que as pessoas são capazes de fazer ou ser, Nussbaum formulou uma lista de capacitações humanas centrais. Ao mesmo tempo, os autores compartilham da mesma ideia da importância das perspectivas éticas para as capacitações, bem como das liberdades politicas, tanto do ponto de vista individual quanto coletivo. 
Quadro 1 - Comparativo entre os principais teóricos da abordagem das capacitações

\begin{tabular}{|l|l|}
\hline Amartya Sen (2000, 2001) & Martha Nussbaum (2000, 2011) \\
\hline $\begin{array}{l}\text { Capacidade como o espaço de comparação para } \\
\text { fins de avaliação da qualidade de vida. }\end{array}$ & $\begin{array}{l}\text { Abordagem das capacitações como a base para } \\
\text { uma teoria parcial da justiça. }\end{array}$ \\
\hline $\begin{array}{l}\text { As políticas devem se concentrar no que as pessoas } \\
\text { são capazes de fazer e ser, na qualidade de vida e } \\
\text { na remoção de obstáculos para que tenham mais } \\
\text { liberdade. }\end{array}$ & $\begin{array}{l}\text { O governo deve garantir princípios políticos a todos } \\
\text { os seus cidadãos através de sua Constituição. }\end{array}$ \\
\hline $\begin{array}{l}\text { Sempre se recusou a endossar uma lista bem } \\
\text { definida de capacidades, pois uma lista pode } \\
\text { depender da finalidade e do contexto, e deve } \\
\text { ser um resultado do raciocínio público e da } \\
\text { democracia. }\end{array}$ & $\begin{array}{l}\text { Desenvolveu e defendeu uma lista bem definida, } \\
\text { mas geral de capacidades humanas centrais. }\end{array}$ \\
\hline $\begin{array}{l}\text { As capacidades são o que ele chama de “liberdades } \\
\text { substantivas", um conjunto de oportunidades } \\
\text { (geralmente inter-relacionadas) para escolher e e } \\
\text { agir. }\end{array}$ & $\begin{array}{l}\text { A lista das dez capacidades centrais: vida; } \\
\text { saúde corporal; integridade corporal; sentidos, } \\
\text { imánão e pensamento; emoções; razão } \\
\text { srática; afiliação; outras espécies; toque; controle } \\
\text { sobre o ambiente. }\end{array}$ \\
\hline $\begin{array}{l}\text { Não são apenas habilidades residindo dentro } \\
\text { de uma pessoa, mas também as liberdades ou } \\
\text { oportunidades criadas por uma combinação de } \\
\text { habilidades pessoais e ambientes político, social e } \\
\text { econômico. }\end{array}$ & $\begin{array}{l}\text { Todas as capacidades são distintas entre si e } \\
\text { precisam ser protegidas, e cada capacidade tem } \\
\text { importância por si própria, com todos os cidadãos } \\
\text { devendo ser elevados acima do limiar em todas as } \\
\text { capacidades. }\end{array}$ \\
\hline $\begin{array}{l}\text { Argumenta como se todas as capacidades fossem } \\
\text { valiosas zonas de liberdade e como se a tarefa } \\
\text { social em geral pudesse ser maximizar a liberdade. }\end{array}$ & $\begin{array}{l}\text { Compromete-se com o conteúdo, utilizando as } \\
\text { dez capacidades centrais como base para a ideia } \\
\text { de direitos políticos fundamentais e direitos } \\
\text { constitucionais. }\end{array}$ \\
\hline
\end{tabular}

Fontes: Elaborado a partir de SEN $(2000,2001)$ e NUSSBAUM $(2000,2011)$.

A abordagem de capacidades parte de uma tradição em economia que mede o valor real de um conjunto de opções pelo melhor uso que pode ser feito deles. As opções são liberdades, e a liberdade tem valor intrínseco (NUSSBAUM, 2011). Dessa forma, a visão da liberdade adotada por Sen (2000) envolve tanto os processos que permitem a liberdade de ações e decisões como as oportunidades reais que as pessoas têm, dadas as circunstâncias pessoais e sociais. Estas liberdades reforçam as capacidades das pessoas, mas também se completam umas às outras, trazendo-se mutuamente um reforço suplementar. O que é importante, em última análise, é que as pessoas têm as liberdades ou oportunidades valiosas para liderar o tipo de vida que desejam, fazer o que querem e ser a pessoa que querem ser. Sendo assim, depois de efetivamente possuir essas oportunidades substantivas, elas podem escolher as opções que mais valorizam (ROBEYNS, 2005).

Tendo isso em vista, o desenvolvimento pode ser considerado como a expansão das liberdades que uma pessoa possui e as liberdades substantivas estão entre os componentes constitutivos do desenvolvimento. O fato é que essas liberdades e os direitos também contribuem muito eficazmente para o progresso econômico (SEN, 2000). Possuir liberdade para fazer as coisas que valoriza faz com que uma pessoa atribua mais valor a si e melhora sua condição de obter resultados. Além disso, a liberdade não determina apenas o sucesso ou fracasso, mas também é um importante determinante da iniciativa individual e da eficácia social (SEN, 2000). 
Além do mais, a capacidade de uma pessoa refere-se às combinações alternativas de funcionamentos que são viáveis para ela alcançar. Um funcionamento é uma realização ativa de uma ou mais capacidades (NUSSBAUM, 2011). De acordo com a abordagem das capacitações, os fins do bem-estar, da justiça e do desenvolvimento devem ser conceituados em termos das capacidades de funcionamento das pessoas, ou seja, suas oportunidades efetivas de empreender as ações e atividades que eles querem participar, e ser quem eles querem ser. Funcionamentos incluem trabalhar, descansar, ser alfabetizado, ser saudável, fazer parte de uma comunidade, ser respeitado, e assim por diante. Segundo Sen (2001), o bem-estar de uma pessoa pode ser concebido em termos da qualidade do "estado" da pessoa, e viver pode ser visto como consistindo num conjunto de funcionamentos inter-relacionados, que compreendem estados e ações.

Relacionada intimamente com a noção de funcionamentos, está a noção de capacidade para realizar funcionamentos, que representa as várias combinações de funcionamentos (estados e ações) que uma pessoa pode realizar. Segundo Sen (2001), a capacidade é um conjunto de vetores de funcionamentos, refletindo a liberdade da pessoa para levar um tipo de vida ou outro. A relevância da capacidade de uma pessoa para seu bem-estar surge de duas considerações distintas, porém inter-relacionadas. Primeiro, se os funcionamentos realizados constituem o bem-estar de uma pessoa, então a capacidade para realizar funcionamentos constituirá a liberdade da pessoa - as oportunidades reais - para ter bem-estar.

A segunda conexão entre bem-estar e capacidade, de acordo com Sen (2000, 2001), consiste diretamente em fazer o próprio bem-estar realizado depender da capacidade para realizar funcionamentos. Escolher pode ser em si uma parte valiosa do viver e uma vida de escolha genuína com opções representativas pode ser concebida - por essa razão - como mais rica e uma escolha com qualidade. Nesta concepção, pelo menos alguns tipos de capacidades contribuem diretamente para o bem-estar, tornando a vida de uma pessoa mais rica de oportunidades de escolha refletida. Mesmo, no entanto, quando a liberdade na forma de capacidade é valorada apenas instrumentalmente, a capacidade para realizar funcionamentos pode ser, ainda assim, uma parte importante da avaliação social (SEN, 2001).

Diante do exposto, entende-se que para o aumento da qualidade de vida de uma nação é necessário que as pessoas tenham direito de escolha, para que possam viver e valorizar a vida que escolheram, e o direito à participação ativa e livre ao longo do processo de desenvolvimento. Isso se justifica uma vez que "o desenvolvimento consiste na eliminação de privações de liberdade que limitam as escolhas e as oportunidades das pessoas de exercerem ponderadamente sua condição de agente" (SEN, 2000). Para que isso seja possível, entretanto, é necessário que haja o suporte de diversas instituições que estimulem e valorizem esse processo. Propõe-se assim a união da abordagem do design thinking como uma forma de operacionalizar as capacidades humanas, e um complemento na busca por soluções que possibilitem uma maior qualidade de vida e consequente aumento das liberdades substantivas às pessoas. 


\section{DESIGN THINKING: CONCEITOS E PROCESSOS}

A expressão design thinking ganhou atenção nos últimos anos em uma ampla gama de contextos além do campo tradicional do design (KIMBELL, 2011). Geralmente é relacionado com o processo de como os designers trabalham, e refere-se a introduzir os métodos e a cultura do design para além do seu campo de atuação (GLOPPEN, 2009; CHANG; KIM; JOO, 2013). Especificamente, a maneira como designers profissionais resolvem problemas pode gerar valor para sociedades que estão tentando fazer a mudança acontecer (KIMBELL, 2011). Brown e Katz (2011) afirmam que o design thinking visa à tradução de observações em ideias, e em produtos e serviços que possam melhorar vidas.

Design thinking é uma expressão que se originou com acadêmicos que conduziram pesquisas dentro de disciplinas de design na década de 60 , e inicialmente buscava compreender os processos e os métodos dos designers nas suas atividades de design, e gradualmente migrou para a investigação do design thinking (KIMBELL, 2011). Herbert Simon é referência no campo acadêmico do design e do design thinking por iniciar as pesquisas na área (BROWN; MARTIN, 2015), e no livro The Sciences of the Artificial, em 1969, criou uma estrutura objetiva para o campo do design, com um rigoroso campo de conhecimento sobre os processos de design (SIMON, 1969).

A natureza complexa de muitos problemas de design surgiu com o trabalho de Hoerst Rittel, em 1972, que foi ampliado na publicação de Rittel e Webber (1973), na qual afirmavam que muitos problemas de design eram complexos de forma que não poderiam ser resolvidos por técnicas científicas e de engenharia. Segundo eles, estes são problemas caracterizados por condições de alta incerteza e que não possuem formulações e soluções definitivas (LIEDTKA, 2015; MAHMOUD-JOUINI; MIDLER; SILBERZAHN, 2016). Nesse mesmo contexto, Buchanan (1992) também relacionou a maneira dos designers pensarem com a resolução de problemas complexos, pois eles possuem uma maneira única de olhar para os problemas e encontrar soluções, na qual a incerteza e a complexidade são aceitas e reconhecidas.

Hoje, entretanto, o discurso do design thinking está mais situado nos desafios que as organizações enfrentam, e menos baseado em pesquisas de design ou em estudos de gestão e organização (KIMBELL, 2011). Nessa perspectiva, o conceito compreende as práticas de design e a forma como os designers fazem sentido de seu próprio trabalho e estendem sua maneira de pensar para pessoas que não são designers (JOHANSSON-SKÖLDBERG; WOODILLA; ÇETINKAYA, 2013). O design thinking é uma abordagem centrada no ser humano para a resolução de problemas, criatividade e inovação ao invés de se referir às disciplinas de design clássico (CARLGREN; RAUTH; ELMQUIST, 2016).

Tendo isso em vista, o design thinking é uma abordagem centrada no ser humano para a resolução de problemas e é conduzida focando os sujeitos, destacando-se a empatia como um de seus princípios essenciais (LIEDTKA, 2015; KIMBELL, 2011; CARLGREN; RAUTH; ELMQUIST, 2016). O grande diferencial do design thinking é a maneira como seus elementos individuais são combinados, sendo um conjunto de abordagens, atitudes e ferramentas que quando juntos integram todas as pontas na resolução de problemas (LIEDTKA, 2015). 
Buscando atender às necessidades das pessoas com soluções tecnologicamente viáveis, o design thinking utiliza a sensibilidade e os métodos dos designers para poder gerar valor para os clientes e oportunidades de mercado (BROWN, 2008). Fica assim claro que o design thinking está relacionado a uma maneira de pensar semelhante a dos designers, sendo esta uma forma de raciocínio capaz de produzir inovações transformadoras (GLOPPEN, 2009). Esta maneira de pensar pode possibilitar que as pessoas identifiquem problemas e gerem soluções mais eficientemente (CHANG; KIM; JOO, 2013).

O design thinking pode ser ainda mais eficaz quando aplicado ao gerenciamento dos desafios intangíveis (BROWN; MARTIN, 2015). Por ser caracterizado como uma metodologia de resolução de problemas (LIEDTKA, 2015), muitas vezes o design thinking e os designers lidam com problemas complexos (RYLANDER, 2009; BUCHANAN, 1992). Estes problemas caracterizam-se por serem mal-definidos, com exigências incompletas, contraditórias e mutáveis (RYLANDER, 2009; MAHMOUD-JOUINI; MIDLER; SILBERZAHN, 2016). Cabe destacar que os grandes desafios que o planeta enfrenta não têm limites disciplinares, são responsabilidade de todos, e exigem que equipes trabalhem juntas combinando conhecimentos em prol de um objetivo comum (YAJIMA, 2015). Independentemente de qual seja o resultado do processo de design, as soluções são projetadas visando a resolver problemas e dificuldades experimentadas pelas pessoas (MAHMOUD-JOUINI; MIDLER; SILBERZAHN, 2016).

Ressalta-se, entretanto, que o design thinking não pretende resolver tudo, mas pode ser uma ótima estratégia para a inovação, pode auxiliar a estimar dados, e pode contribuir para as pessoas e organizações atravessarem situações complexas (KOLKO, 2015). Além disso, é uma abordagem que busca antecipar as demandas e atender às necessidades das pessoas, que muitas vezes não são explícitas, por meio de produtos intuitivos e confortáveis de usar (WARD; RUNCIE; MORRIS, 2009). Isso só é possível porque o design thinking é um processo essencialmente empático, que tem como valores essenciais ser orientado e centrado no ser humano (LIEDTKA, 2015).

A empatia é um valor que considera todas as partes envolvidas, sejam clientes, sujeitos ou colegas, e busca imaginar o mundo a partir de suas perspectivas, colocando-se no lugar do outro (MAHMOUD-JOUINI; MIDLER; SILBERZAHN, 2016). Dessa forma, uma abordagem centrada nos sujeitos precisa compreender os problemas a partir de suas perspectivas e durante todo o processo de desenvolvimento deve testar as suposições feitas com sujeitos reais (WARD; RUNCIE; MORRIS, 2009). Sendo assim, o design thinking pode ser uma oportunidade de criar novas possibilidades, proporcionar novas escolhas e oferecer novas soluções para o mundo (BROWN; KATZ, 2011).

Seu processo é iterativo e se move desde a geração de insights sobre as necessidades das pessoas, passando pela geração de ideias e testes, que busca rapidamente criar soluções por meio de prototipagem, com desenvolvimento de protótipos simples, até a solução final e a sua efetivação (KIMBELL, 2011; LUCHS, 2015). O design thinking possui uma estrutura que integra modos criativos e analíticos de raciocínio, bem como um conjunto de ferramentas e técnicas. Seu processo baseia-se na abdução e no aprendizado mediante a experimentação, e é mais adequado para contextos de decisão em que há grande incerteza e ambiguidade (LIEDTKA, 2015). 
Diversos autores descreveram o processo com fases distintas, porém, basicamente, é por meio de ciclos iterativos de exploração que o processo ocorre (LIEDTKA, 2015). Ao invés de uma sequência de passos ordenados, o processo de design thinking pode ser descrito metaforicamente como um sistema de espaços que demarcam diferentes tipos de atividades relacionadas (BROWN, 2008). Conforme ilustrado na Figura 1, o processo possui, inicialmente, uma fase de compreensão do problema e identifição das necessidades dos sujeitos, por intermédio de coleta de dados que definirá os critérios do projeto; uma segunda fase de conceituação e geração de ideias; e uma terceira fase de prototipagem, testes e seleção das ideias desenvolvidas (BROWN, 2008; LIEDTKA, 2015; SEIDEL; FIXSON, 2013). Após finalizado o processo a solução é lançada ao mercado e sofre constante avaliação e evolução.

Figura 1 - Etapas do processo de design thinking

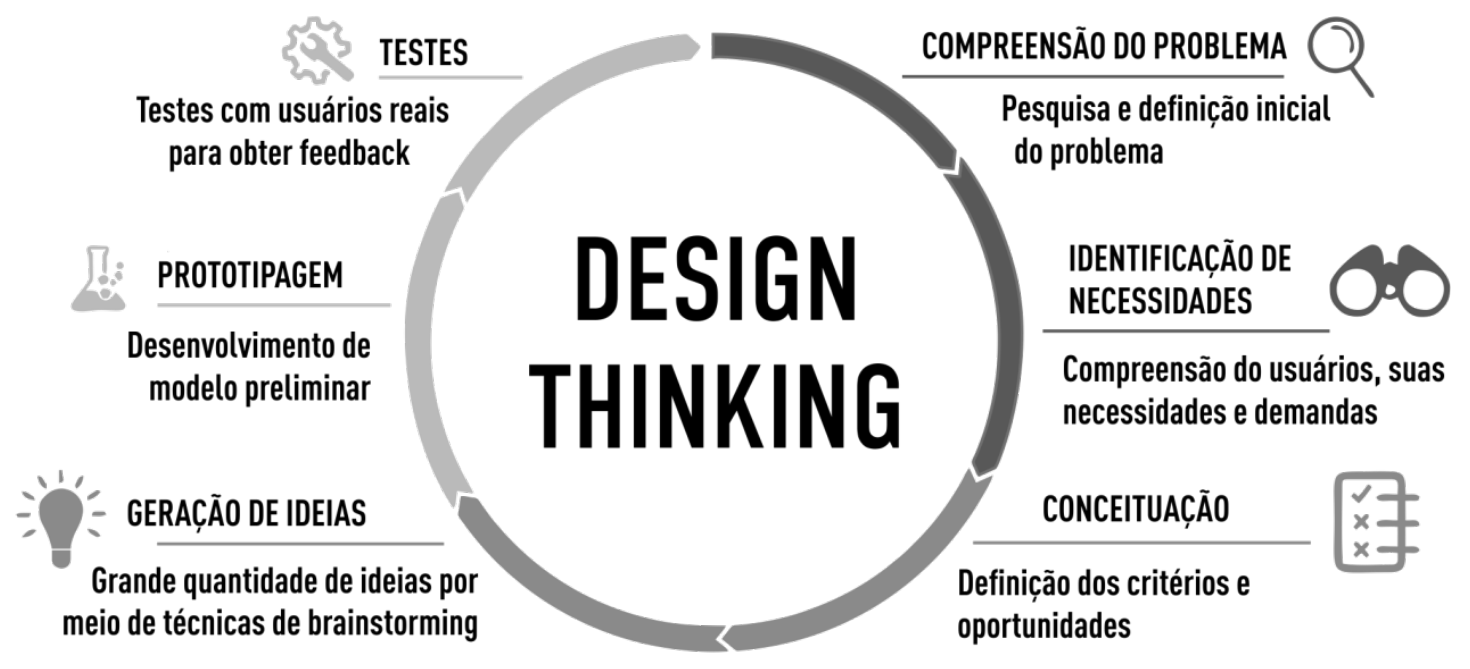

Fonte: Elaborado a partir de BROWN (2008); LIEDTKA (2015); SEIDEL; FIXSON (2013).

Assim, entende-se que todas as características descritas que compõem a abordagem do design thinking podem ser grandes alavancas na solução dos desafios que compõem o desenvolvimento de uma sociedade. Além disso, por ser voltado para as pessoas e para a solução de suas necessidades, acredita-se que o design thinking pode potencializar ainda mais a abordagem das capacitações e auxiliar na criação de capacidades que possam trazer bem-estar e qualidade de vida às pessoas.

\section{INTER-RELAÇÃO ENTRE AS ABORDAGENS}

Ao propor a integração entre as duas abordagens, buscou-se identificar aspectos que possibilitassem verificar e compreender as semelhanças e diferenças entre elas, a fim de refletir sobre como operacionalizar tal integração. Inicialmente identificou-se que a principal característica que possibilita a integração das duas abordagens é o seu foco nas pessoas. O design thinking está associado a ter uma abordagem centrada no ser humano para a resolução de problemas (KIMBELL, 2011), e a centralidade da abordagem das capacitações são as capacidades humanas. Assim, o design thinking busca entender as pessoas profundamente, seus gostos, suas necessidades, para poder converter estes aspectos do comportamento em valor e benefícios (BROWN, 2008). 
Além disso, o design está fundamentado na dignidade humana e nos direitos humanos (BUCHANAN, 2001). Sen (2000) declarou que as capacidades humanas e os direitos humanos são conceitos intimamente ligados. Nesse sentido, o design thinking apresenta sua visão centrada no ser humano, no qual, ao invés de um produto ou serviço, os seres humanos e as suas necessidades, práticas e preferências são colocados no centro de um processo de design. Mais precisamente, o design centrado no ser humano é uma busca contínua do que pode ser feito para apoiar e fortalecer a dignidade dos seres humanos à medida que eles representam suas vidas em variadas circunstâncias sociais, econômicas, políticas e culturais (BUCHANAN, 2001).

Além do mais, os princípios de design thinking têm o potencial de serem ainda mais eficazes quando direcionados à resolução de desafios intangíveis (BROWN; MARTIN, 2015). Por ser caracterizado como uma metodologia de resolução de problemas (LIEDTKA, 2015), diversas vezes o design thinking e os designers lidam com problemas complexos (RYLANDER, 2009; BUCHANAN, 1992). Independentemente de qual seja o resultado do processo de design, seja um produto, um sistema, uma interface ou uma experiência, as soluções são projetadas visando a resolver problemas e dificuldades experimentadas pelas pessoas (MAHMOUD-JOUINI; MIDLER; SILBERZAHN, 2016).

O design oferece uma maneira de pensar sobre o mundo que é importante para superar muitos dos problemas que os seres humanos enfrentam na cultura contemporânea, e a atenção consciente para a forma como os designers trabalham em áreas especializadas de aplicação, tais como comunicação ou design industrial é relevante para o trabalho em outras áreas. Assim, a maneira de resolver problemas design thinking é importante para fornecer ferramentas e enfrentar os desafios que os seres humanos encontram em seus ambientes (BUCHANAN, 2001), e pode auxiliar na eliminação das privações de liberdades que limitam as escolhas e oportunidades das pessoas.

O design thinking é potencialmente universal em seu escopo porque pode ser aplicado para qualquer área da experiência humana (BUCHANAN, 1992). Além disso, a abordagem pode ser aplicada a todas as áreas profissionais, não ficando restrita apenas ao campo de design, podendo auxiliar a resolver problemas de maneiras inovadoras, com o poder de resolver alguns problemas extremamente complexos (CLARK; SMITH, 2008). Ao colocar o design thinking em ação, pessoas que não são do campo do design podem desenvolver iniciativas que impulsionem seus campos de atuação, bem como novas soluções que gerem impacto positivo (INNS, 2013). Ao estender seus princípios a outras áreas, o design thinking busca envolver diversos atores no processo de inovação, por meio de equipes multidisciplinares e propõe ferramentas, processos e metodologias para facilitar essas interações (ACKLIN, 2010; SEIDEL; FIXSON, 2013; MAHMOUD-JOUINI; MIDLER; SILBERZAHN, 2016). Nesse mesmo sentido, Alkire (2005) e Robeyns (2005) concebem a abordagem das capacitações como multidisciplinar, defendendo que haja uma colaboração entre a abordagem e outros campos de atuação.

Dentre as diferenças entre as duas abordagens ressalta-se que a concepção de liberdade política e democracia, aspectos primordiais da abordagem das capacitações, são pouco abordados no design thinking. Além disso, os demais tipos de liberdades instrumentais identificados por Sen (2000), como as facilidades econômicas e a segurança protetora, também são pouco explorados pela abordagem do design. Sabe-se, entretanto, que o desenvolvimento está ligado ao exercício das liberdades instrumentais das 
pessoas, (ANDRADE et al., 2016), e é necessária uma preocupação com a utilização conjunta de todas as liberdades instrumentais, visto que elas se suplementam mutuamente (SEN, 2000).

Ademais, outra diferença a ser ressaltada é o fato de a abordagem das capacitações preocupar-se em mapear e ressaltar todos os aspectos da vida humana a serem preservados (SEN, 2000), porém com um olhar mais conceitual e teórico. Por outro lado, o design thinking foca na resolução de problemas e geração efetiva de soluções, a partir da integração das pessoas em seus processos, de forma mais prática e empírica (LIEDTKA, 2015; WARD; RUNCIE; MORRIS, 2009). Sendo assim, tal diferença poderia ser positiva na operacionalização da integração entre as abordagens, visto que o design thinking poderia auxiliar a tornar mais prática e aplicada a abordagem das capacitações.

Por fim, outro ponto a ser observado é que ambas as abordagens possuem dificuldades de medir os seus resultados. No design thinking existe uma complexidade de medir e avaliar os resultados e a contribuição de suas atividades por não haver um instrumento específico para medição e por não ser possível isolá-lo de outros parâmetros (RAUTH; CARLGREN; ELMQUIST, 2015). Já na abordagem das capacitações, sabe-se que é dificil medir os resultados da expansão das capacidades e das liberdades das pessoas, visto que cada capacidade utiliza insumos diferentes, como recursos financeiros, práticas políticas, práticas sociais ou mesmo tradições e hábitos (ROBEYNS, 2005). Além disso, Alkire (2005) afirma que os resultados vão depender de como cada país utiliza e aborda os problemas em questão, e de seu nível de ação.

Diante do exposto, sabe-se que o design thinking não é a solução para todos os problemas da sociedade, e que muito precisa ser explorado e estudado para que tal integração ocorra de fato. Em destaque, questões como política e legislação também precisam ser consideradas, além das demais liberdades instrumentais. Apesar disso, acredita-se que a integração das duas abordagens pode ser muito promissora na busca por soluções aos desafios e na remoção dos obstáculos que limitam a qualidade de vida das pessoas. Sendo assim, a Figura 2 apresenta uma sistematização de como as abordagens poderiam se integrar e de como podem ser utilizadas conjuntamente.

Figura 2 - Integração entre as abordagens

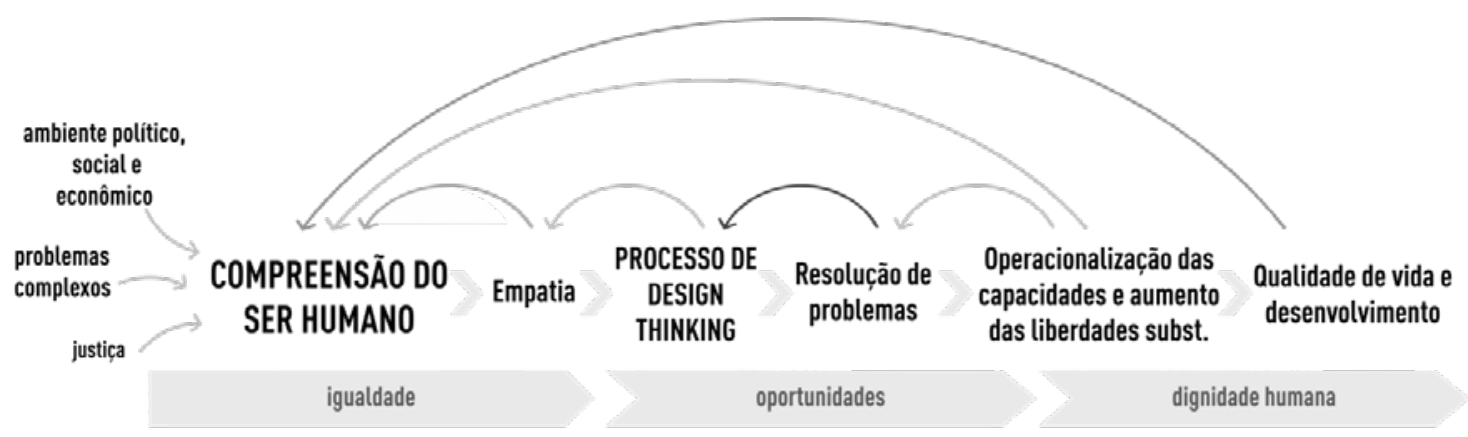

Fonte: Elaborado pelos autores, 2017.

Todos os aspectos da abordagem das capacitações precisam que haja uma compreensão do ser humano, gerando empatia, que é também o aspecto central do design thinking. Somente a partir do entendimento profundo de suas realidades e necessidades é possível desenvolver soluções que possibilitem liberdades, igualdade e direitos 
que transformem a vida das pessoas e que resolvam os desafios intangíveis. Essa integração pode oferecer uma nova forma de olhar o ser humano, e o design thinking pode atuar como uma forma de operacionalizar e potencializar as capacidades humanas. Os resultados de tal integração são soluções que proporcionam maior qualidade de vida e desenvolvimento, por meio do aumento das liberdades substantivas das pessoas.

Propõe-se assim que tal união utilize o design thinking como um meio para operacionalizar as capacidades humanas, possibilitando que as instituições que podem impactar no desenvolvimento humano e social possuam uma alternativa bem como um complemento na busca por soluções que possibilitem mais liberdade às pessoas. As instituições podem ser mais bem apreciadas por seu lado instrumental relacionado às questões de desenvolvimento (ANDRADE et al., 2016), e tal integração seria potencializada se utilizada por empresas com forte impacto social, instituições públicas e privadas, ou mesmo entidades governamentais e entidades sociais. Tal utilização poderia ocorrer em âmbito local, regional ou nacional, alternando somente a ordem de complexidade decisória

Outro ponto no qual pode ser aplicada tal integração é na utilização da abordagem das capacitações no desenvolvimento de novas tecnologias e produtos para países em desenvolvimento, com o objetivo de expandir as capacidades humanas (OOSTERLAKEN, 2009). A autora afirma que a aplicação da abordagem das capacitações relacionada com a tecnologia, engenharia e design pode gerar impactos enormes. Nesse sentido, o design thinking pode contribuir para a humanização da tecnologia e para o desenvolvimento de soluções que alcancem o emocional, visto que é uma ferramenta essencial para simplificar e humanizar processos (KOLKO, 2015).

\section{CONSIDERAÇÕES FINAIS}

Diante do exposto, compreende-se a necessidade de um olhar mais cuidadoso sobre os diversos desafios que as sociedades atuais enfrentam, que vão desde problemas de saúde básica, educação, a problemas de desenvolvimento, justiça, entre outros. Esses desafios, por vezes, limitam as oportunidades das pessoas, que sem o mínimo de condições para viver uma vida com dignidade, não tem opções de escolha, e nem a liberdade de viver a vida que desejam e que valorizam.

Ao propor a integração do design thinking com a abordagem das capacitações, buscou-se refletir sobre a possibilidade de contribuir na ampliação das liberdades e capacidades das pessoas. Conclui-se que esta integração pode ser uma forma de contribuir com o alargamento das liberdades substantivas individuais e grupais e na solução dos problemas complexos enfrentados pelas nações, por meio da utilização dos processos e valores do design thinking na solução dos desafios encontrados pelas nações.

Dessa forma, o design thinking pode ser visto como uma abordagem que pode contribuir na busca por soluções, por parte de instituições, empresas e governantes, que possibilitem reduzir as dificuldades que as pessoas enfrentam e que limitam as suas liberdades substantivas. Essa integração entre as abordagens pode ser um caminho para instituições em todos os níveis da sociedade, tanto para a esfera pública, com a aplicação para governantes, quanto para empresas, como para entidades. Pode fornecer um 
novo olhar e ser uma estratégia para os diversos problemas complexos que a sociedade enfrenta hoje. Em síntese, pode fornecer uma estratégia a todos que se preocupam sobre em que mundo gostariam de viver.

Esta, entretanto, é apenas uma discussão inicial, e há ainda muito a ser explorado sobre as perspectivas apresentadas. Entende-se, também, que como possibilidade de estudos futuros, essa integração necessita ser explorada de forma empírica, visando a testar se os constructos se consolidam na solução de desafios reais, e a Figura 2 pode ser a base para elaboração do instrumento empírico. Mais precisamente, a teoria pode ser aplicada visando a testar se os processos de design thinking se confirmam na solução dos problemas complexos e se, de fato, contribuem para a ampliação das liberdades substantivas.

\section{REFERÊNCIAS}

ACKLIN, C. Design-driven innovation process model. Design Management Journal, v. 5, n. 1, p. 50-60, 2010.

ALKIRE, S. Why the Capability Approach? Journal of Human Development, v. 6, p. 115-135, 2005.

ANDRADE, S. F. et al. Índice de desenvolvimento como liberdade: uma proposta teórico-metodológica de análise. In: Desenvolvimento em Questão, v. 14, n. 34, p. 5-59, jan. 2016.

BROWN, T. Design Thinking. Harvard Business Review, v. 86, p. 84-92, 2008.

BROWN, T.; KATZ, B. Change by design. Journal of Product Innovation Management, v. 28, p. 381-383, 2011.

BROWN, T.; MARTIN, R. Design for Action. Harvard Business Review, v. 93, n. 9, p. 56-64, Sept. 2015.

BUCHANAN, R. Wicked Problems in Design Thinking. Design Issues, v. 8, n.22, p. 5-21, 1992.

BUCHANAN, R. Human dignity and human rights: thoughts on the principles of human-centered design. Design Issues, v. 17, n. 3, p. 35-39, 2001.

CARLGREN, L.; RAUTH, I.; ELMQUIST, M. Framing design thinking: the concept in idea and enactment. Creativity and Innovation Management, v. 25, n. 1, p. 38-57, 2016.

CHANG, Y.; KIM, J.; JOO, J. An exploratory study on the evolution of design thinking: comparison of Apple and Samsung. Design Management Journal, v. 8, n. 1, p. 22-34, 2013.

CLARK, K.; SMITH, R. Unleashing the power of design thinking. Design Management Review, v. 19, n. 3, p. 8-15, 2008.

FRITZ, K. B. B. A insegurança alimentar no rural do Rio Grande do Sul: análise da privação de uma capacidade básica. 2009. Tese (Doutorado em Desenvolvimento Rural) - Universidade do Rio Grande do Sul, Faculdade de Ciências Econômicas, Programa de Pós-Graduação em Desenvolvimento Rural, 2009.

GLOPPEN, J. Perspectives on design leadership and design thinking and how they relate to European service industries. Design Management Journal, v. 4, n. 1, p. 33-47, 2009.

INNS, T. Theaters for design thinking. Design Management Review, v. 24, n. 2, p. 40-47, 2013.

JOHANSSON-SKÖLDBERG, U.; WOODILLA, J.; ÇETINKAYA, M. Design thinking: past, present and possible futures. Creativity and Innovation Management, v. 22, n. 2, p. 121-146, 2013.

KERSTENETZKY, C. L. Welfare State e Desenvolvimento. Dados - Revista de Ciências Sociais, Rio de Janeiro, v. 54, n. 1, p. 129-156, 2011.

KIMBELL, L. Rethinking design thinking: part I. Design and culture, v. 3, n. 3, p. 285-306, 2011.

KOLKO, J. Design Thinking Comes of Age. Harvard Business Review, v. 93, n. 9, p. 66-71, Sept. 2015.

LIEDTKA, J. Perspective: linking design thinking with innovation outcomes through cognitive bias reduction. Journal of Product Innovation Management, v. 32, n. 6, p. 925-938, 2015.

LUCHS, M.G. A brief introduction to design thinking. In: LUCHS, M. G.; SWAN, K. S.; GRIFFIN, A. Design thinking: new product development essentials from the PDMA. New Jersey: John Wiley \& Sons, 2015. p. 1-11.

MAHMOUD-JOUINI, S. B.; MIDLER, C.; SILBERZAHN, P. Contributions of design thinking to project management in an innovation context. Project Management Journal, v. 47, v. 2, p. 144-156, 2016.

NUSSBAUM, M. C. Women and human development. Cambridge: Cambridge University Press, 2000. 
NUSSBAUM, M. C. Creating capabilities: the human development approach. Cambridge: Harvard University Press, 2011.

OOSTERLAKEN, I. Design for Development: A Capability Approach. Design Issues, v. 25, n. 4, p. 91-102, 2009.

PNUD. Programa Nacional das Nações Unidas. Desenvolvimento humano e IDH. Disponível em: http:// www.br.undp.org/content/brazil/pt/home/idh0/conceitos.html. Acesso em: 18 jul. 2018.

RAUTH, I.; CARLGREN, L.; ELMQUIST, M. Making It Happen: Legitimizing Design thinking in Large Organizations. Design Management Journal, v. 9, n. 1, p. 47-60, 2015.

RITTEL, H.; WEBBER, M. Dilemmas in a General Theory of Planning. Policy Sciences, v. 4, p. 155-169, 1973. ROBEYNS, I. The Capability Approach: a theoretical survey. Journal of Human Development, v. 6, n. 1, p. 93-117, 2005.

RYLANDER, A. Design thinking as knowledge work: epistemological foundations and practical implications. Design Management Journal, v. 4, p. 7-19, 2009.

SEIDEL, V. P.; FIXSON, S. K. Adopting "design thinking" in novice multidisciplinary teams: The application and limits of design methods and reflexive practices. Journal of Product Innovation Management, v. 30, n.1, p. 19-33, 2013.

SEN, A. Desenvolvimento como liberdade. São Paulo: Companhia das Letras, 2000.

SEN, A. Desigualdade reexaminada. Rio de Janeiro: Record, 2001.

SEN, A. A ideia de justiça. Tradução Denise Bottmann e Ricardo Doninelli Mendes. São Paulo: Companhia das Letras, 2011.

SHAPIRA, H.; KETCHIE, A.; MERET, N. The integration of Design Thinking and Strategic Sustainable Development. Journal of Cleaner Production, v. 140, p. 277-287, 2017.

SIMON, H. A. The Sciences of the Artificial. Cambridge, Mass: MIT Press, 1969.

WARD, A.; RUNCIE, E.; MORRIS, L. Embedding innovation: design thinking for small enterprises. Journal of Business Strategy, v. 30, n. 2, p. 78-84, 2009.

YAJIMA, R. Catalyzing Scientific Innovation with Design Thinking. Design Management Review, v. 26, n. 1, p. 18-23, 2015.

ZAMBAM, J. N. Amartya Sen: liberdade, justiça e desenvolvimento sustentável. Passo Fundo: Passo Fundo: Imed, 2012. 